\title{
Quantification of mRNA in Chloroplasts of Chlamydomonas reinhardii: Equal Distribution of mRNA for a Soluble and a Membrane Polypeptide in Stroma and Thylakoids
}

\author{
Eric Breidenbach, Erika Jenni, Stefan Leu ${ }^{1}$ and Arminio Boschetti ${ }^{2}$ \\ Institut für Biochemie der Universität Bern, Freiestr. 3, CH-3012 Bern, Switzerland
}

\begin{abstract}
The relative contents of the mRNAs were analyzed for the $32 \mathrm{kDa}$ herbicide-binding protein and for the large subunit of ribulose-1,5-bisphosphate carboxylase in the membrane fraction and in the soluble fraction of chloroplasts from Chlamydomonas reinhardii. The presence of mRNA for the two proteins in both subchloroplast fractions was demonstrated by in vitro translation of isolated RNA in the reticulocyte lysate. The relative amounts of the two mRNAs were measured by hybridizations with cloned chloroplast DNA probes at two stages of the cell cycle. Both mRNAs were distributed in the same ratio between membrane and soluble fractions, about $75 \%$ of both mRNAs being in the membrane and $25 \%$ in the soluble fraction. Therefore, in chloroplasts the accumulation of mRNAs on thylakoid membranes does not reflect the final localization of soluble and membrane proteins.
\end{abstract}

Key words: Chlamydomonas reinhardii - Chloroplast (Polysome) - mRNA content $-32 \mathrm{kDa}$ herbicide-binding protein - Ribulose-1,5-bisphosphate carboxylase (Large subunit).

In chloroplasts, thylakoid-bound polysomes are present (Margulies and Michaels 1975, Bolli et al. 1981) in varying amounts during the cell cycle (Bolli et al. 1981, Chua et al. 1976). The functional significance of the membranebinding is not clear. By translating polysomes bound to thylakoids of Chlamydomonas, Margulies et al. (1975) found that essentially all terminated polypeptide chains remained with thylakoids, and thus were incorporated cotranslationally into the membranes as they were synthesized. The comparison of the translational capabilities of free and bound chloroplast ribosomes from pea suggested a functional difference between these polysome species (Ellis 1977, 1981). After incubation of the membrane-free, soluble chloroplast fraction with ATP, GTP and ${ }^{35} \mathrm{~S}$-methionine, most of the translation products of

\footnotetext{
Abbreviations: $\mathrm{CF}_{1}$, coupling factor $1 ; 32 \mathrm{kDa}$ protein, $32 \mathrm{kDa}$ herbicide-binding membrane protein; LS, large subunit of ribulose-1,5-bisphosphate carboxylase; Rubisco, ribulose-1,5bisphosphate carboxylase; SSPE, $0.18 \mathrm{M} \mathrm{NaCl}, 1 \mathrm{~mm}$ EDTA, $10 \mathrm{~mm}$ Na-phosphate pH 7.4.

1 Present address: Department of Biology, Ben Gurion University, Beer-Sheva, Israel.

2 To whom correspondence and reprint requests should be addressed.
}

free chloroplast ribosomes were released as soluble proteins, the main product being the LS. In contrast, all radioactive products synthesized by thylakoid-bound ribosomes remained with the membrane even after puromycin treatment, and hence, were thought to be hydrophobic polypeptides. Subsequently, several workers (Alscher et al. 1978, Herrin et al. 1981, Herrin and Michaels 1985, Margulies 1983, Bhaya and Jagendorf 1984) confirmed that the "function of thylakoid-bound ribosomes is to synthesize thylakoid membrane proteins" (Herrin et al. 1981). The finding that the extrinsic $a$ - and $\beta$-subunits of $\mathrm{CF}_{1}$ are synthesized on both free and membrane-bound polysomes of pea chloroplasts (Bhaya and Jagendorf 1985) supported the idea that the hydrophobicity of the proteins determines their site of synthesis.

A new aspect arose from the work of Leu et al. (1984) and Minami and Watanabe (1984). They found different protein products after so-called run-off translation of thylakoid-bound polysomes and of stromal polysomes and ribosomes. However, no difference among the product patterns was observed, when RNA extracted from thylakoids or stroma was translated in a heterologous translation system. With both extracts the LS and the $32 \mathrm{kDa}$ protein were produced. Recently, Hattori and Margulies (1986) also found that the LS was produced by thylakoids 
of spinach in an E. coli translation system and concluded translatable mRNA for LS to be present in thylakoidbound polysomes. Unfortunately, the direct quantitative determination of mRNA via its translation product is not accurate, what we demonstrate in the present paper. Interestingly, Marzuki and Hibbs (1986) also found that in yeast mitochondria a hydrophilic protein, the var 1 protein, is synthesized on membrane-associated mitochondrial ribosomes and that these ribosomes cannot be distinguished from those responsible for the synthesis of the hydrophobic mitochondrial translation products.

To clarify the questions on mRNA localization in chloroplast, the mRNA contents for a membrane and a soluble chloroplast protein should be measured simultaneously in stroma and thylakoid fractions from isolated chloroplasts. Since evidence has been presented for the variation of total amount of chloroplast RNAs and mRNAs during the cell cycle of Chlamydomonas (Herrin et al. 1986, Howell and Walker 1977), the mRNA contents should be determined for at least two different stages of the cell cycle.

Therefore, at half time and at the end of the light period of synchronized cultures of Chlamydomonas reinhardii we determined the amounts of mRNAs for LS and $32 \mathrm{kDa}$ protein by hybridization with cloned DNAfragments, in order to compare the distribution of mRNAs between stroma (free polysomes) and thylakoids (membrane-bound polysomes), and to estimate the extent of mRNA binding to thylakoids.

\section{Materials and Methods}

Chloroplast isolation-Chloroplasts were isolated as previously described (Mendiola-Morgenthaler et al. 1985) at the 6th and 13th hour of a light period from synchronized cultures ( $14 \mathrm{~h}$ light $/ 10 \mathrm{~h}$ dark) of Chlamydomonas reinhardii $\mathrm{cw}-15$ (stock CC-1615 from Chlamydomonas Genetics Center, Duke University, Durham, NC). The cells were incubated with $200 \mu \mathrm{g} / \mathrm{ml}$ chloramphenicol for $20 \mathrm{~min}$ before harvesting. The homogenization medium contained $100 \mu \mathrm{g} / \mathrm{ml}$ chloramphenicol. The isolated chloroplasts were washed twice in the homogenization medium without chloramphenicol prior to fractionation. The ribosomal subunit composition of chloroplasts and chloroplast fractions was analyzed as previously described (Bolli et al. 1981).

Fractionation of chloroplasts-Isolated chloroplasts were sedimented and carefully resuspended in $25 \mathrm{mM} \mathrm{Mg-}$

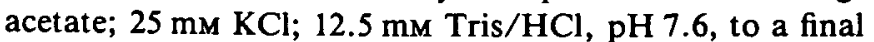
concentration of $1 \mathrm{mg} / \mathrm{ml}$ chlorophyll. After they had been broken in the Yeda-Press at 25-30 atmospheres (2.5$3 \times 10^{6} \mathrm{~Pa}$ ), the resulting homogenate was adjusted to $25 \mathrm{~mm} \mathrm{Mg}$-acetate; $200 \mathrm{mM} \mathrm{KCl} ; 40 \mathrm{~mm}$ Tris $/ \mathrm{HCl} \mathrm{pH} \mathrm{7.6;}$ $10 \mathrm{~mm} 2$-mercaptoethanol. The supernatant obtained by centrifugation at $39,000 \times g$ for $15 \mathrm{~min}$ was free of chloro- phyll and called the soluble chloroplast fraction. The pellet was washed twice and resuspended to the original volume in the same buffer (membrane fraction).

Extraction of RNA-Chloroplasts or chloroplast fractions were solubilized in $1 \%$ sodium laurylsarcosinate and extracted once with phenol (equilibrated with $\mathrm{Tris} / \mathrm{HCl}$, pH 8.0, and containing $0.1 \%$ hydroxyquinoline and $0.2 \%$ 2-mercaptoethanol), once with phenol/chloroform/isoamyl alcohol $25: 24: 1(\mathrm{v} / \mathrm{v} / \mathrm{v})$ and once with chloroform/ isoamyl alcohol $24: 1(\mathrm{v} / \mathrm{v})$. The RNA was precipitated with ethanol. The dry RNA was dissolved in double distilled water. The amounts of RNA were measured spectrophotometrically and expressed as $A_{260}$ units.

In vitro translation-In vitro translation in the reticulocyte lysate was done following the instructions of the manufacturer (NEN). Products were analyzed by polyacrylamide gel electrophoresis followed by fluorography (Leu et al. 1984). The intensity of labeling of the two main products was determined by integration of the densitograms obtained after different exposure times.

Cloned DNA probes-Plasmids pEC8 and pEC23 containing the Chlamydomonas chloroplast DNA EcoRI fragment R15 and R14, respectively, were isolated and characterized by Herrin and Michaels (1985 and personal communication). Plasmid R $15 / 4$ was obtained from J. -D. Rochaix (University of Geneva) and contains a HindIII internal fragment of the Chlamydomonas LS gene (Dron et al. 1982).

Northern blot and dot blot analysis-RNA was separated in $1.5 \%$ agarose $6 \%$ formaldehyde gels (Maniatis et al. 1982), transferred immediately onto nitrocellulose filter and hybridized with labeled DNA probes (Herrin and Michaels 1984). As molecular weight standards rRNA of $E$. coli were separated on the same gel and stained with Acridine Orange. For dot blot hybridization, the RNA was denatured with $50 \%$ formamide, $6 \%$ formaldehyde in SSPE at $50^{\circ} \mathrm{C}$. Subsequently, the buffer concentration was adjusted to $4.4 \times$ SSPE and the solution was applied to nitrocellulose filter using a Bio-Dot microfiltration apparatus (Bio Rad).

\section{Results}

Chloroplasts of Chlamydomonas reinhardii were isolated in the presence of chloramphenicol and separated into soluble and membrane fractions. From the analysis of the ribosomal subunits in these fractions (Fig. 1) the absence of cytoplasmic ribosomes can be seen. About $55 \%$ of the chloroplast ribosomes were found in the membranes, about $35 \%$ in the soluble fraction, and the rest was lost during fractionation (Table 1). From isolated chloroplasts, we extracted about 7.1 A $_{260}$ units RNA per mg chlorophyll. When total RNA was extracted from the chloroplast fractions, $63 \%$ of the RNA was recovered from 


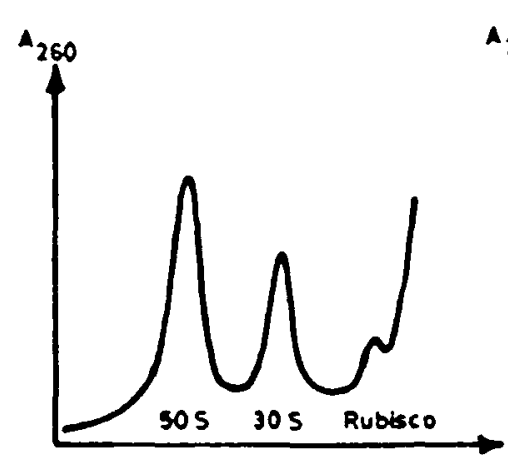

C

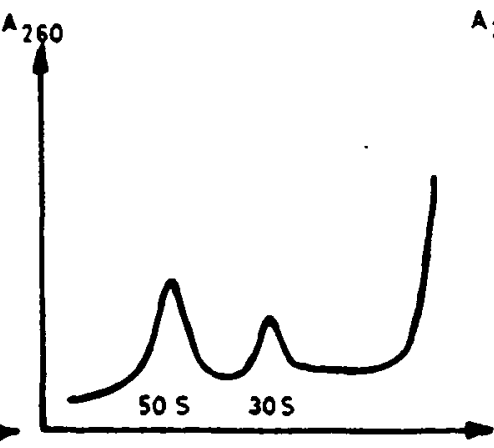

m

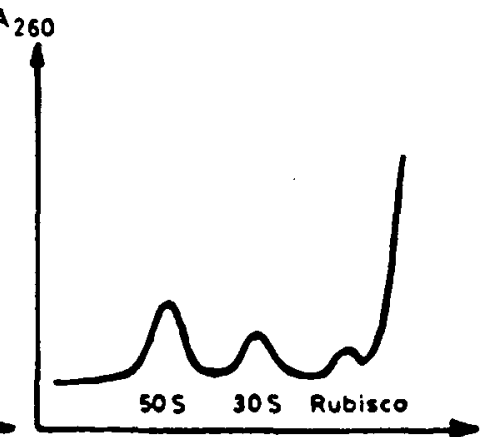

$\mathbf{S}$

Fig. 1 Analysis of ribosomal subunits of whole chloroplasts (c), chloroplast membranes (m) and soluble fraction (s). ribosomal subunits were isolated and analyzed by centrifugation on sucrose density gradients.

the thylakoids and $37 \%$ from the stroma (Table 1). Thus, within the limits of determination this ratio was comparable to the ratio of ribosomes recovered from the same fractions (Table 1).

The RNAs from whole chloroplasts, membranes and soluble fraction were translated in vitro using a reticulocyte lysate. The main products, previously identified as the LS $(55 \mathrm{kDa})$ and the $34 \mathrm{kDa}$ precursor of the $32 \mathrm{kDa}$ protein (Leu et al. 1984), were labeled by in vitro translation of RNAs from all three fractions (Fig. 2), showing that intact mRNAs for both proteins are present in the soluble and in the membrane fractions. However, depending on the amount of total RNA present in the incubation mixture, the relative labeling intensities of $\mathrm{LS}$ and $32 \mathrm{kDa}$ protein

Table 1 Amounts of ribosomes and extracted RNA of chloroplasts (c), membranes (m) and soluble (s) fraction

\begin{tabular}{lcc}
\hline & $\begin{array}{c}\text { Chloroplast } \\
\text { ribosomes } \\
(\%)^{a}\end{array}$ & $\begin{array}{c}\text { Extracted } \\
\text { RNA } \\
(\%)^{b}\end{array}$ \\
\hline Whole chloroplasts (c) & 100 & - \\
Membrane fraction (m) & 55 & 63 \\
Soluble fraction (s) & 35 & 37 \\
Ratio (m/s) & 1.6 & 1.7
\end{tabular}

a The distribution of chloroplast ribosomes was determined by measuring the area of the peaks of the densitograms of Fig. 1.

${ }^{b}$ RNA was extracted from chloroplast membranes (m) and soluble fraction (s) with the phenol/chloroform procedure. Here, the sum of extracted RNA of $(m+s)$ was taken as $100 \%$. precursor were quite different. Therefore, such in vitro translation should not be used for quantitative determinations of mRNA (Fig. 2).

The relative contents of the mRNAs for the LS and for the $32 \mathrm{kDa}$ protein were determined by hybridization with the cloned EcoRI fragments of chloroplast DNA from Chlamydomonas reinhardii, namely pEC8 or $15 / 4$, hybridizing to the LS mRNA (Dron et al. 1982, Rochaix 1981), and pEC23, containing a part of the $32 \mathrm{kDa}$ protein gene (psbA) and hybridizing to the $32 \mathrm{kDa}$ protein mRNA (Harrin and Michaels 1984, 1985, Rochaix 1981). By hybridizing the labeled DNA probes to Northern blots of chloroplast RNA (Fig. 3), labeled bands were visible at $1.5 \mathrm{~kb}$ and $1.2 \mathrm{~kb}$, representing the mRNAs for LS and $32 \mathrm{kDa}$ protein, respectively. Furthermore, the autoradiograms clearly demonstrate a higher content of LS mRNA in the membrane fraction than in the soluble fraction (Fig. 3).

Fig. 3 also demonstrates the intactness of isolated mRNA and the specificities of our DNA probes. Therefore, in the following experiments we used dot blot hybridization to measure relative mRNA contents in whole chloroplasts, membranes and soluble fraction at the two indicated stages of the cell cycle. By this method it was possible to quantify a large number of RNA samples under strictly identical conditions to allow direct comparison of the results. The results in Table 2 show, (i) that the mRNAs for the soluble protein $\mathrm{LS}$, and for the $32 \mathrm{kDa}$ membrane protein are present in the same ratio in the RNA extracted from membranes and in the RNA from the soluble fraction, (ii) that these mRNAs are enriched in the RNA from the membrane fraction, while their content in the RNA from the soluble fraction is about half as much as in the thylakoids, and (iii) that these findings are essentialy the same at the 6 th and 13 th $\mathrm{h}$ of the light period. 


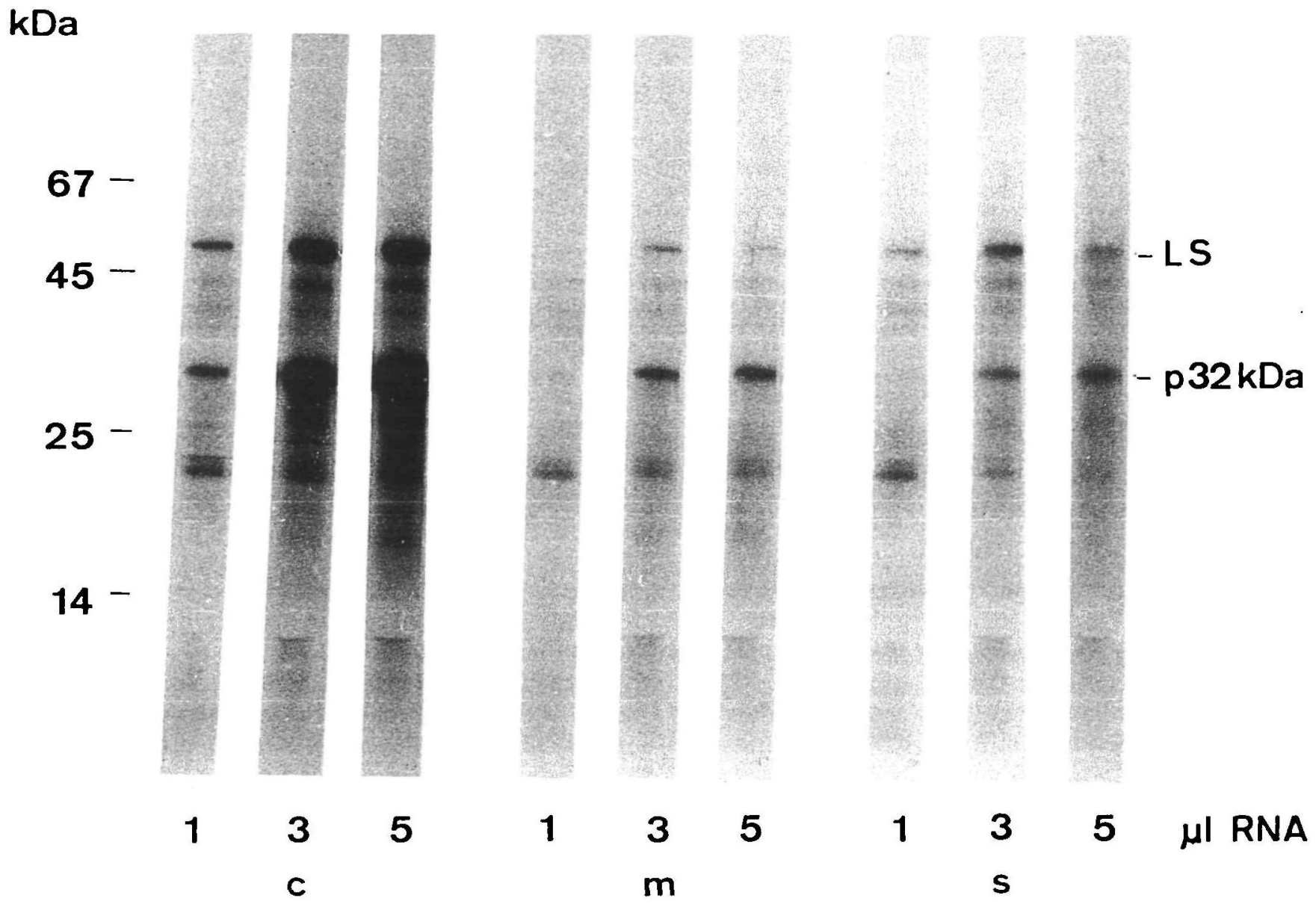

Fig. 2 Fluorogram of the products of in vitro translation in reticulocyte lysate. RNAs were extracted from whole chloroplasts (c), membrane $(\mathrm{m})$ and soluble (s) fractions. For each type of RNA, the product patterns of three incubations with increasing amounts of RNA (0.025, 0.075, 0.125 A260 units per $15 \mu$ l reaction mixture, respectively) are shown. In controls without added RNA, no radioactive bands were detected.

\section{Discussion}

In vitro translation of isolated RNA from chloroplasts and subchloroplast fractions and identification of the two main products (Leu et al. 1984) showed that mRNAs for the soluble (LS) and the membrane protein $(32 \mathrm{kDa}$ protein) are present in both the soluble and the membrane fraction of the chloroplast (Fig. 2). However, the amount of mRNAs in each fraction could not be determined quantitatively by translation experiments, because protein synthesis activity was not linearly related to the amount of RNA added (Fig. 2). Therefore, for the determination of the relative mRNA contents, we used hybridization techniques.

If the membrane-bound polysomes predominantly synthesize membrane polypeptides, the polysomes can be expected to be enriched with respect to mRNAs for membrane polypeptides, while free polysomes should predominantly contain mRNAs for soluble proteins. Indeed, in working with whole cells of Chlamydomonas instead of isolated chloroplasts, Herrin and Michaels (1985) concluded from their hybridization experiments that the mRNA for the $32 \mathrm{kDa}$ protein is associated with thylakoidbound polysomes and not present in the soluble cell fraction. However, a comparison of the amounts of RNA isolated from whole cells of Chlamydomonas (Herrin and Michaels 1984, Valle et al. 1981) and from isolated chloroplasts (this work) shows that chloroplast RNA is about $10-20 \%$ of total cell RNA. Therefore, the large amount of cytoplasmic RNA in their soluble fraction of whole cells should have obscured the presence of mRNA for the $32 \mathrm{kDa}$ protein.

We extracted the RNA from isolated chloroplasts and 


\section{pEC23 pEC8}

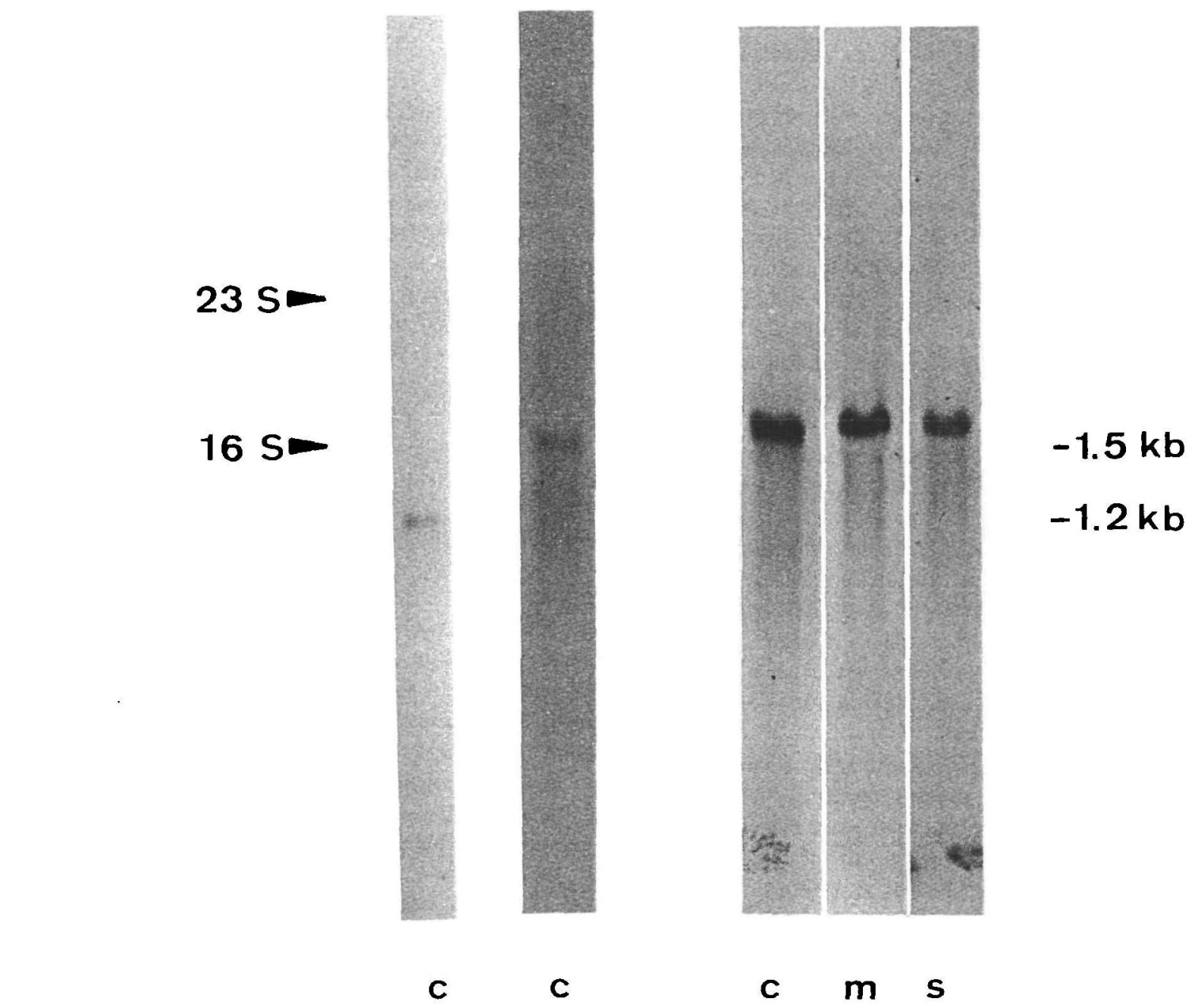

\section{$15 / 4$}

Fig. 3 Autoradiograms of Northern blot hybridizations with nicktranslated plasmids from pEC8 or 15/4 (LS-gene) and pEC23 (32 kDa gene). RNA, $0.125 \mathrm{~A}_{260}$ units from chloroplasts (c), membrane fraction (m) and stroma (s) were separated electrophoretically. Arrows indicate the migration distance of rRNA of $E$. coli.

Table 2 Relative mRNA contents in RNAs extracted from whole chloroplasts and from the membrane and soluble fractions as determined by dot-blot hybridization

\begin{tabular}{|c|c|c|c|c|c|}
\hline \multirow[t]{2}{*}{ Harvesting of cells: } & \multicolumn{3}{|c|}{6 th $h$ of light period } & \multicolumn{2}{|c|}{ 13th $\mathrm{h}$ of light period } \\
\hline & $\begin{array}{c}32 \mathrm{kDa} \\
(\mathrm{pEC} 23)\end{array}$ & $\begin{array}{c}\text { LS } \\
\text { (pEC8) }\end{array}$ & $\begin{array}{c}\mathrm{LS} \\
(15 / 4)\end{array}$ & $\begin{array}{c}32 \mathrm{kDa} \\
(\mathrm{pEC} 23)\end{array}$ & $\begin{array}{c}\text { LS } \\
(15 / 4)\end{array}$ \\
\hline Whole chloroplast & 1 & 1 & 1 & 1 & 1 \\
\hline Membrane & $1.21(0.09)$ & $1.36(0.11)$ & 1.23 & $1.21(0.05)$ & $1.44(0.10)$ \\
\hline Soluble & $0.47(0.03)$ & $0.53(0.10)$ & 0.59 & $0.66(0.11)$ & $0.62(0.20)$ \\
\hline No. of experiments & 3 & 5 & 1 & 3 & 3 \\
\hline
\end{tabular}

Of each RNA 0.01 and $0.05 \mathrm{~A}_{260}$ units were blotted on nitrocellulose filter. The mRNA contents of chloroplast RNA, determined with each DNA probe, were normalized to unity. The values for the RNAs of the chloroplast fractions were calculated relative to unity. In parenthesis: standard deviation. 
our results show, that the mRNAs for the LS and for the $32 \mathrm{kDa}$ protein occur in about the same ratio in the soluble and the membrane fractions (Table 2), suggesting that the distribution of mRNAs for membrane and soluble proteins does not differ between the soluble and the membrane chloroplast compartments. This agrees with the results of run-off translation showing that some membrane polypeptides can be synthesized by free polysomes (Bhaya and Jagendorf 1985) and that a soluble polypeptide can be synthesized by membrane-bound polysomes (Hattori and Margulies 1986).

Furthermore, we have shown that in RNA extracted from chloroplast membranes the mRNA content is about twice that in RNA from the soluble fraction (Table 2). Together with the fact that the membrane fraction contains also about 1.6 times more RNA as the soluble fraction (Table 1), we calculate that in chloroplasts, about $75 \%$ of the mRNAs for both the soluble and membrane polypeptides occur in membrane-bound form, while only about $25 \%$ seem to occur in the stroma.

Finally, during the second half of the light period of the cell cycle, when potein synthesis declines gradually as measured by ${ }^{35} \mathrm{SO}_{4}$ incorporation (Howell et al. 1977), the mRNA distribution and the relative mRNA contents in membrane and soluble fractions are constant (Table 2). Whether this constancy is maintained during the whole cells cycle, remains to be determined.

In the light of these results, thylakoids seem to be a most important site of chloroplast protein synthesis. Furthermore, since there are differences in the products labeled by free and membrane-bound polysomes in run-off translation (Ellis 1977, Leu et al. 1984, Minami and Watanabe 1984), there must be a mechanism in each of these chloroplast compartments by which the translation of selected mRNAs is controlled.

We thank D. Herrin, Tampa/Athens and J.-D. Rochaix, Geneva for their generous gifts of the cloned DNA probes. This work was supported by the Swiss National Foundation for Scientific Research. E. B. received a fellowship from the Roche Research Foundation, Basel.

\section{References}

Alscher, R., Patterson, R. and Jagendorf, A. T. (1978) Activity of thylakoid-bound ribosomes in pea chloroplasts. Plant Physiol. 62: 88-93.

Bhaya, D. and Jagendorf, A. T. (1984) Synthesis of subunit III of $\mathrm{CF}_{0}$ by thylakoid-bound polysomes from pea chloroplasts. Plant Mol. Biol. 3: 277-280.

Bhaya, D. and Jagendorf, A. T. (1985) Synthesis of the $a$-and $\beta$ subunits of coupling factor 1 by polysomes from pea chloroplasts. Arch. Biochem. Biophys. 237: 217-223.
Bolli, R., Mendiola-Morgenthaler, L. and Boschetti, A. (1981) Isolation and characterization of polysomes from thylakoid membranes of Chlamydomonas reinhardii. Biochim. Biophys. Acta 653: 276-287.

Chua, N. H., Blobel, G., Siekewitz, P. and Palade, G. E. (1976) Periodic variations in the ratio of free to thylakoid-bound chloroplast ribosomes during the cell cycle of Chlamydomonas reinhardii. J. Cell Biol. 71: 497-514.

Dron, M., Rahire, M. and Rochaix, J.-D. (1982) Sequence of the chloroplast DNA region of Chlamydomonas reinhardtii containing the gene of the large subunit of ribulose-bisphosphate carboxylase and parts of its flanking genes. J. Mol. Biol. 162: 775-793.

Ellis, R. J. (1977) Protein synthesis by isolated chloroplasts. Biochim. Biophys. Acta 463: 185-215.

Ellis, R. J. (1981) Chloroplast proteins: Synthesis, transport and assembly, Annu. Rev. Plant Physiol. 32: 111-137.

Hattori, T. and Margulies, M. M. (1986) Synthesis of large subunit of ribulosebisphosphate carboxylase by thylakoidbound polyribosomes from spinach chloroplasts. Arch. Biochem. Biophys. 244: 630-640.

Herrin, D., Michaels, A. and Hickey, E. (1981) Synthesis of chloroplast membrane polypeptide on thylakoid-bound ribosomes during the cell cycle of Chlamydomonas reinhardii $137^{+}$. Biochim. Biophys. Acta 655: 136-145.

Herrin, D. and Michaels, A. (1984) Isolation, fractionation and analysis of intact, translatable RNA from walled algal cells. Plant Mol. Biol. Rep. 2: 24-28.

Herrin, D. and Michaels, A. (1985) The chloroplast $32 \mathrm{kDa}$ protein is synthesized on thylakoid-bound ribosomes in Chlamydomonas reinhardtii. FEBS Lett. 184: 90-95.

Herrin, D. L., Michaels, A. S. and Paul, A. L. (1986) Regulation of genes encoding the large subunit of ribulose-1,5-bisphosphate carboxylase and the photosystem II polypeptides D-1 and D-2 during the cell cycle of Chlamydomonas reinhardtii. J. Cell Biol. 103: 1837-1845.

Howell, S. H., Posakony, J. W. and Hill, K. R. (1977) The cell cycle programm of polypeptide labeling in Chlamydomonas reinhardtii. J. Cell Biol. 72: 223-241.

Howell, S. H. and Walker, L. L. (1977) Transcription of the nuclear and chloroplast genomes during the vegetative cell cycle in Chlamydomonas reinhardii. Dev. Biol. 56: 11-23.

Leu, S., Bolli, R., Mendiola-Morgenthaler, L. and Boschetti, A. (1984) In-vitro translation of different mRNA-containing fractions of Chlamydomonas chloroplasts. Planta 160: 204-211.

Maniatis, T., Fritsch, E. F. and Sambrook, J. (1982) Molecular Cloning: A Laboatory Manual. pp. 202-203. Cold Spring Harbor Laboratory, New York, Cold Spring Harbor.

Margulies, M. M. (1983) Synthesis of photosynthetic membrane proteins directed by RNA from rough thylakoids of Chlamydomonas reinhardtii. Eur. J. Biochem. 137: 241-248.

Margulies, M. M. and Michaels, A. (1975) Free and membranebound chloroplast polyribosomes in Chlamydomonas reinhardtii. Biochim. Biophys. Acta 402: 297-302.

Margulies, M. M., Triffany, H. L. and Michaels, A. (1975) Vec- 
torial discharge of nascent polypeptides attached to chloroplast thylakoid membranes. Biochem. Biophys. Res. Commun. 64: 735-739.

Marzuki, S. and Hibbs, A. R. (1986) Are all mitochondrial translation products synthesized on membrane-bound ribosomes? Biochim. Biophys. Acta 866: 120-124.

Mendiola-Morgenthaler, L., Leu, S. and Boschetti, A. (1985) Isolation of biochemically active chloroplasts from Chlamydomonas. Plant Science 38: 33-39.
Minami, E.-I. and Watanabe, A. (1984) Thylakoid membranes: the translational site of chloroplast DNA-regulated thylakoid polypeptides. Arch. Biochem. Biophys. 235: 562-570.

Rochaix, J. D. (1981) Organization, function and expression of the chloroplast DNA of Chlamydomonas reinhardii. Experientia 37: $323-332$.

Valle, O., Lien, T. and Knutsen, G. (1981) Fluorometric determination of DNA and RNA in Chlamydomonas using ethidium bromide. J. Biochem. Biophys. Methods 4: 271-277.

(Received April 28, 1987; Accepted September 29, 1987) 